\title{
CARTOGRAFIA GEOTÉCNICA DA REGIÃO DE MOGI-GUAÇU, SÃO PAULO
}

\author{
Giuliano DE MIO \\ Nilson GANDOLFI
}

\section{RESUMO}

\begin{abstract}
A Cartografia Geotécnica é ferramenta básica em qualquer trabalho de planejamento da ocupação. Apresenta utilização ainda restrita devido à sua pouca divulgação. Neste trabalho é apresentada a Cartografia Geotécnica da Quadrícula de Mogi-Guaçu, com os mapas do substrato rochoso e de materiais de cobertura, e a avaliação geotécnica realizada através de uma tabela de propriedades geotécnicas referenciada ao mapa de materiais de cobertura.
\end{abstract}

\section{ABSTRACT}

Engineering geological mapping is an essential tool in planning the development of countries. It has had restricted use due to poor divulgation. This work presentes the engineering geological mapping of Mogi-Guaçu Region, with maps of rock substract and surface materials. The geotechnical evaluation is lithogenetic, referred to surface material units and is presented on a table of geotechnical properties.

\section{INTRODUÇÃO}

A progressiva intensificação na utilização dos terrenos pelo homem, feita de maneira agressiva e inadequada, tem resultado em uma degradação ambiental progressiva e num aumento do custo de implantação das obras. Paralelamente, são constantes os conflitos de uso em diversas regiões.

$\mathrm{O}$ adequado conhecimento do meio físico pode tornar-se útil quando existir vontade política em se executar um planejamento regional de uso e ocupação dos terrenos. Nessa abordagem devem ser avaliados os parâmetros geotécnicos referentes a cada tipo de terreno, sendo que a precisão desta avaliação está intimamente associada à escala de execução dos trabalhos e à disponibilidade de dados. Muitas vezes, em grandes áreas e em pequenas escalas (1:100.000 e menores), a avaliação do comportamento geotécnico global dos solos e rochas pode e deve ser feita qualitativamente, priorizando atributos de fácil obtenção. Com o aumento da escala (1:25.000 ou 1:10.000), podem-se avaliar os parâmetros e atributos geotécnicos de maneira mais precisa, através da realização de uma quantidade representativa de ensaios que resultem na obtenção de parâmetros compatíveis com a aptidão a ser avaliada.
O presente trabalho enfoca os aspectos geotécnicos do terreno considerando como elemento geotécnico básico as unidades de materiais de cobertura, tendo recebido auxílio do CNPq (bolsa) e FINEP/PADCT.

\section{PRINCÍPIOS BÁSICOS DE MAPEAMENTO GEOTÉCNICO}

O Mapeamento Geotécnico pode ser definido como uma ferramenta ou processo que procura caracterizar as propriedades do terreno de interesse para engenharia e planejamento, prevendo as interações entre os processos do meio físico, o homem e suas obras.

Mundialmente, existe uma ampla variedade de metodologias e sistemáticas de execução da cartografia geotécnica desenvolvidas, respeitando características físicas, políticas e sociais dos locais onde foram elaboradas. No entanto, os fatores a serem avaliados são comumente os mesmos em todas elas.

Da análise das diversas metodologias e sistemáticas existentes, observa-se que nenhuma delas pode ser aplicada fora do país ou região onde foi desenvolvida, sem que se realizem mudanças consistentes no seu arcabouço. Portanto, ao se pretender realizar a cartografia geotécnica de uma região, o bom senso da equipe executora é indispensável na obtenção dos objetivos propostos. 
Desta maneira, um trabalho de cartografia geotécnica deve tratar da representação cartográfica das características do meio físico natural de imediato interesse às obras de engenharia. Dentre todos os aspectos a serem analisados, existirão alguns de maior ou menor importância para cada região e que devem ser priorizados em função da relevância que representem na avaliação das características de interesse (ARNOT \& GRANT, 1974).

\section{CARACTERIZAÇÃO DA ÁREA DE ESTUDO}

\subsection{Localização}

A área de estudo situa-se na porção Centro-Leste do Estado de São Paulo, entre os paralelos $22^{\circ} 15^{\prime}$ e $22^{\circ} 30^{\prime}$ e meridianos $46^{\circ} 45^{\prime}$ ' e $47^{\circ} 00^{\prime}$

Abrangendo toda a quadrícula de MogiGuaçu na escala 1:50.000, com área de 715 $\mathrm{Km}^{2}$ (Fig. 1), englobando parte dos municípios de Mogi-Guaçu, Mogi-Mirim, Itapira e Pinhal.

\subsection{Geologia}

A área localiza-se em uma região de transição entre as rochas do Embasamento Cristalino e as da Bacia do Paraná.

Caracteriza-se por forte heterogeneidade litológica, englobando, no Embasamento Cristalino, gnaisses, granitos, xistos, quartzitos e rochas cataclásticas, de Idade Pré-Cambriana, fortemente estruturada (xistosidade, fraturas e falhas) e com freqüentes contatos tectônicos entre as litologias. A porção da bacia do Paraná é constituída por rochas sedimentares pertencentes ao Grupo Tubarão, de idade cabonífera superior, representadas por arenitos, siltitos, argilitos e diamictitos, em uma interdigitação típica de depósitos glaciais. Intrudidos, neste pacote de sedimentos ou no contato embasamento/bacia, ocorrem extensos sills de diabásio, correlacionados ao Grupo São Bento, de idade mesozóica e com baixa heterogeneidade litológica. Ocorrem ainda, capeando as diversas litologias da região, extensos depósitos areno-argilosos com espessuras variáveis, de idade cenozóica e correlacionáveis à Formação Rio Claro.

Um caráter marcante das rochas do embasamento, de grande importância para a engenharia, é o contraste de competência dos pacotes rochosos, seja por diferenças composicionais ou de intensidade de fraturamento e deformação. Este contraste impõe variações bruscas do comportamento geotécnico ao longo de alguns poucos metros.

As unidades geológicas foram separadas em Substrato Rochoso e Materiais de Cobertura; a primeira engloba todas as rochas e a segunda, todos os materiais que recobrem o substrato rochoso, sejam eles residuais ou transportados. As figuras 2 e 3 apresentam as características geológicas da área.

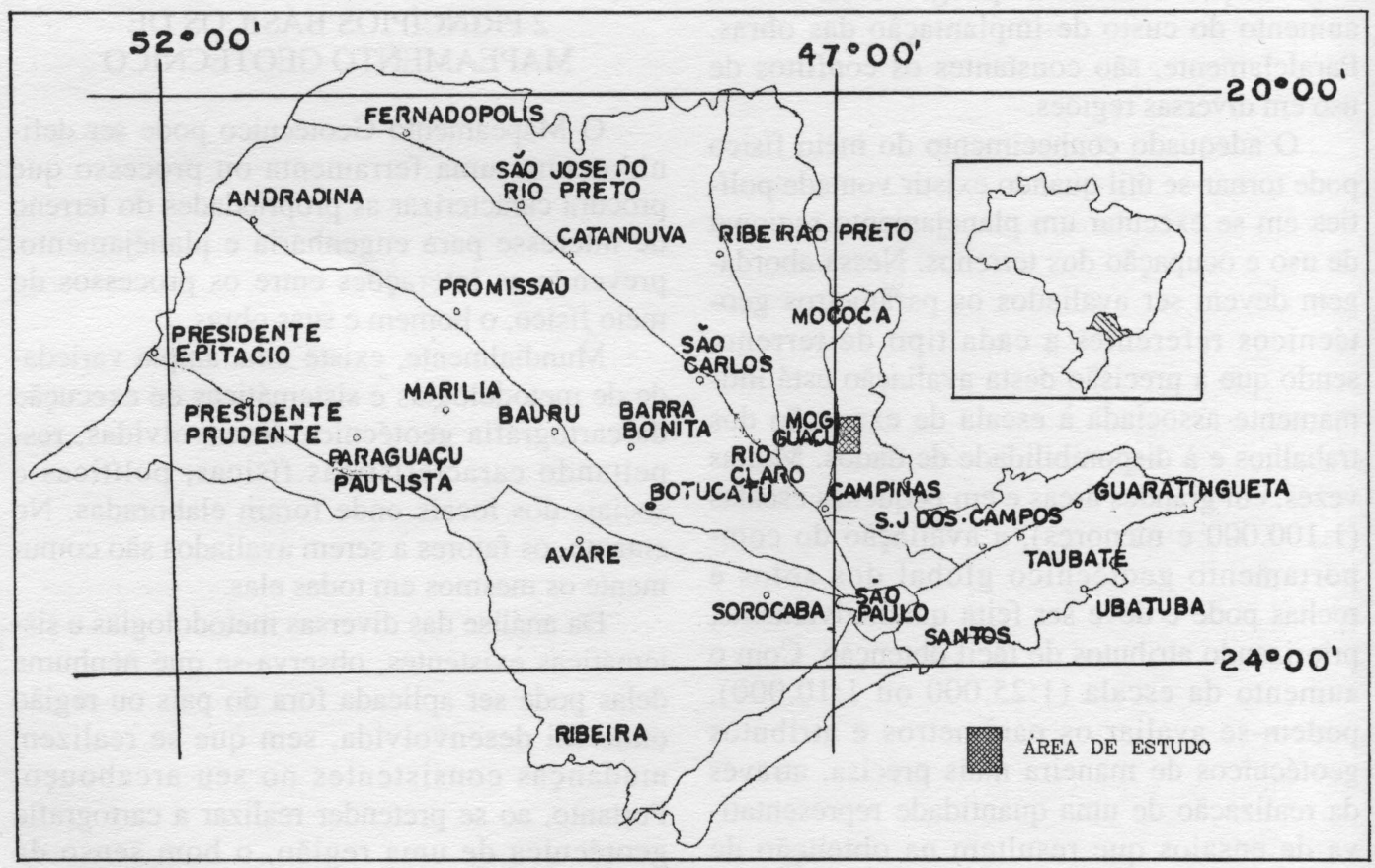

FIGURA 1 - Área de estudo 


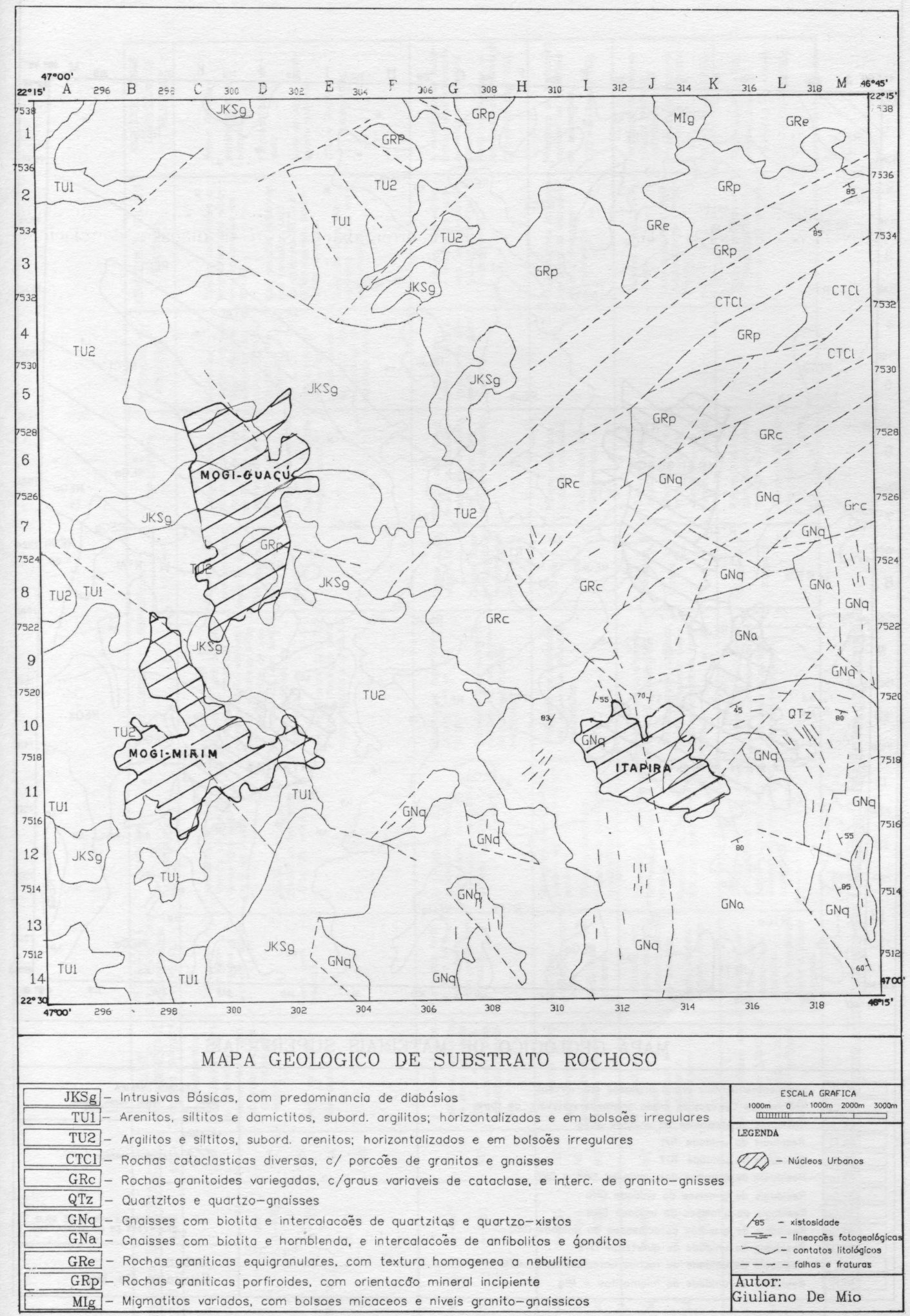

FIGURA 2 - Mapa geológico de substrato rochoso. 


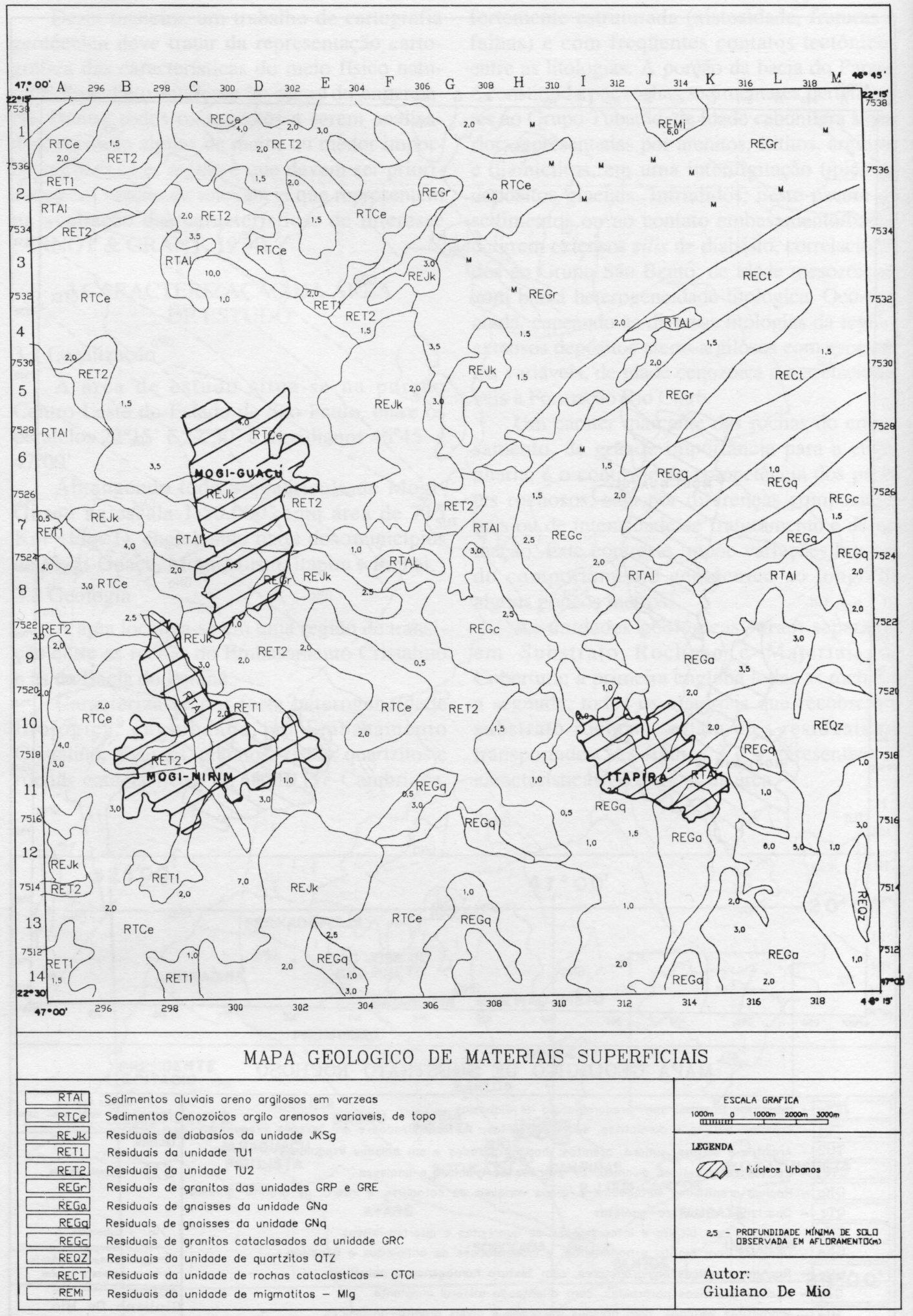

FIGURA 3 - Mapa geológico de materiais superficiais 


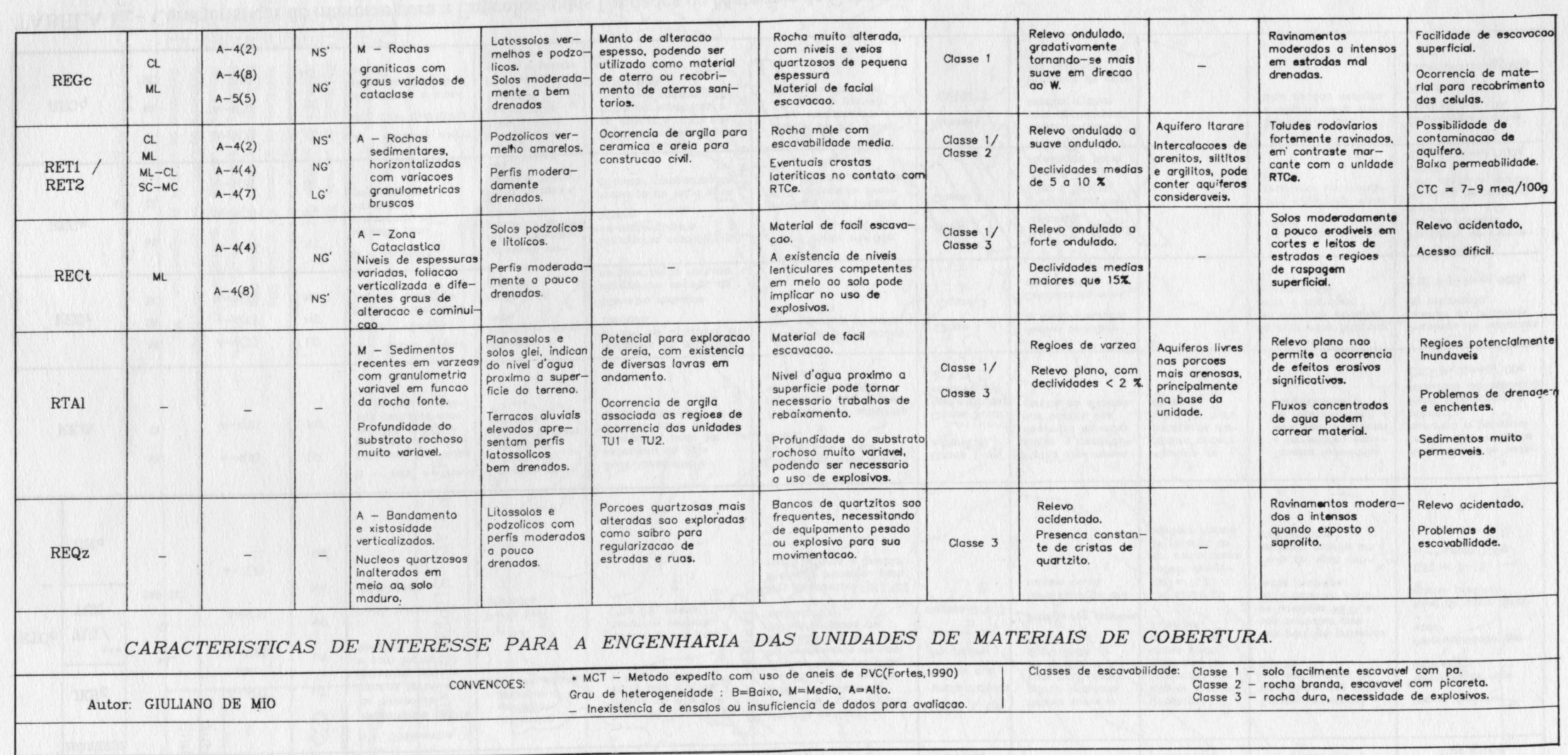

TABELA $1 \mathrm{~b}$ - características de interesse para a Engenharia das Unidades de Materiais de Cobertura 


\section{AVALIAÇÃO GEOTÉCNICA}

A abordagem geotécnica da área seguiu as orientações contidas nas propostas metodológicas de ZUQUETTE (1987) e FINLAYSON (1982), com modificações substanciais em função das características específicas da região. A interpretação das informações geotécnicas foi feita com base em um zoneamento de caráter litogenético, com informações apresentadas na forma de uma tabela referenciada ao mapa de materiais de cobertura, onde são fornecidas características de interesse para a engenharia das diversas unidades (Tab. 1a e 1b). Nelas, são abordadas as classificações geotécnicas dos solos da unidade, o grau de heterogeneidade de cada unidade, pedologia e as características de drenagem do perfil, aspectos relacionados aos materiais de construção, à escavação, à topografia, ao potencial como aqüífero, às feições erosivas e à disposição de rejeitos.

$\mathrm{O}$ trabalho originalmente foi elaborado na escala 1:100.000 (DE MIO, 1992), quando foi também executada uma classificação geomor- fológica dos terrenos, com confecção de um mapa de sistemas de relevo e uma tabela das características geomorfológicas da área, a ser oportunamente publicada.

\section{CONCLUSÕES}

As características geotécnicas dos terrenos devem ser avaliadas tanto na pequena como na grande escala. Em função da disponibilidade de dados, experiência da equipe executora e objetivo do trabalho, o resultado da cartografia geotécnica pode ser apresentado na forma de mapas temáticos ou tabelas interpretativas. A utilização destas tabelas permite condensar um grande número de informações, tornando-as de fácil entendimento.

O intercruzamento de vários mapas (hidrografia, geologia, sistemas de relevo, declividade etc.) permitiu identificar correlações íntimas entre geologia e geomorfologia, sugerindo que o aprofundamento desse tipo de investigação poderá auxiliar a execução da cartografia geotécnica, principalmente em regiões com carências expressivas de dados.

\section{REFERÊNCIAS BIBLIOGRÁFICAS}

ARNOT, F.; GRANT, K. 1974, Land Classification for Urban Growth. DAG, Research Paper n. 230, CSIRO, Austrália, 4(2), p. 28-32.

DE MIO, G. 1992. Mapeamento Geotécnico da Quadrícula de Mogi-Guaçu/SP. Dissertação de Mestrado, Departamento de Geotecnia-EESC/USP, 102 p.
FINLAYSON, A.A. 1982. Terrain Analysis, Classification and Engineering Geological Assessment of the Sydnei area, New South Wales, DAGTP n. 32, CSIRO, Austrália, v. 1 e 2.

ZUQUETTE, L.V. 1987. Análise Crítica da Cartografia Geotécnica e Proposta Metodológica para as Condições Brasileiras. Tese de Doutorado. São Carlos/SP, EESC/USP, 3 vols., 673 p. 